\title{
Modeling and prediction of complex environmental systems
}

\author{
Bellie Sivakumar $\cdot$ Ronny Berndtsson
}

Published online: 23 September 2008

(C) Springer-Verlag 2008

The last century witnessed the development of numerous approaches (e.g. linear, nonlinear, deterministic, stochastic, physics-based, data-based) for modeling and prediction of our complex environmental systems. There is a plethora of literature debating whether any one of these approaches is superior to any other (if at all such an evaluation can be made), and why and how. While such debates continue, an examination of environmental literature also reveals the existence of some serious problems in our modeling practice (see, for example, Beven 2002), regardless of the approach adopted. For example: (1) we have a tendency, driven by our technological and methodological advances, to develop more complex models (having too many parameters and requiring too much data) than that may actually be necessary; and (2) the models are often developed for specific situations, and their extensions to other situations and generalizations are normally difficult. What is also being increasingly realized is that none of the existing approaches is adequate for modeling and prediction of our environmental systems by itself. With our increasing emphasis on specific concepts/methods (see, for example, Sivakumar 2005) for their 'individual brilliance' (that normally reflect our extreme and biased views), rather than their 'collective utility' to address the real environmental challenges, the above situation may not change much in the future, unless a significant change in paradigm

B. Sivakumar $(\square)$

Department of Land, Air and Water Resources,

University of California, Davis, CA 95616, USA

e-mail: sbellie@ucdavis.edu

R. Berndtsson

Department of Water Resources Engineering,

Lund University, 22100 Lund, Sweden

e-mail: ronny.berndtsson@tvrl.lth.se is adopted. The only way to overcome this situation seems to be to find some 'common grounds' in our modeling approaches, which is the primary motivation for this Special Issue entitled "Modeling and Prediction of Complex Environmental Systems." Towards pursuing this, the specific objectives are:

1. to disseminate the latest initiatives and developments in the modeling and prediction of our environmental systems, especially focusing on the applications of different concepts/methods; and

2. to discuss (both philosophically and scientifically) the potential for the formulation of a 'middle-ground' approach for more realistic representations of our environmental systems, and also to highlight the important challenges in this formulation.

This Special Issue consists of 14 papers, contributed by a total of 40 authors. Each paper falls under either of the above two objectives, and collectively they bring forth the applications of various approaches/techniques to different environmental systems/problems around the world. The techniques applied in these papers include (in the order of their appearance), among others: hidden Markov models (Jayawardena et al.; Kwon et al.), wavelet transforms (Jayawardena et al.; Kwon et al.), fractals and multifractals (Cortis et al.), nonlinear dynamics and chaos (Kim et al.; Singh et al.; Sivakumar), artificial neural networks (Aksoy and Dahamsheh; Bagtzoglou and Hossain), nonlinear stochastic models (Cayar and Kavvas), numerical methods (Perera et al.), self-organizing maps (Lischeid), statistical estimation techniques (Bagtzoglou and Hossain; Dean et al.; Vrugt et al.), Bayesian approaches (Bagtzoglou and Hossain; Vrugt et al.), and data-based mechanistic models (Young and Ratto). The environmental problems addressed in these papers are, among others: rainfall (Jayawardena 
et al.; Kwon et al.; Cortis et al.; Kim et al.; Aksoy and Dahamsheh), streamflow (Kim et al.), lake volume (Kim et al.), hydrologic inversion (Bagtzoglou and Hossain), groundwater flow and transport, sea water intrusion, irrigation related salinization (Cayar and Kavvas; Perera et al.), gravel bed dynamics (Singh et al.), uncertainty estimation in rainfall-runoff and water quality models (Dean et al.; Vrugt et al.), global carbon cycle and global climate (Young and Ratto), and a review on the applications of nonlinear dynamic and chaos theories in hydrology (Sivakumar). Environmental data from the USA, the UK, Germany, Japan, Jordan, Korea, and Thailand are analyzed in these studies. Also, three of these studies (Vrugt et al.; Sivakumar; Young and Ratto) are specifically intended to address the need, and also the opportunity, for a 'middleground' approach in environmental modeling and to highlight the associated challenges. The outcomes are both promising and thought-provoking.

The fundamental as well as the applied aspects of the papers in this Special Issue would be beneficial to both theoreticians and practitioners in environmental science and engineering. Stochastic Environmental Research and Risk Assessment (SERRA) has been as an excellent platform for disseminating research initiatives and activities on both conventional and modern concepts for studying environmental systems, and this Special Issue would certainly be a timely addition. It is also hoped that the 'middle-ground' approach, aimed as an important outcome of the present endeavor, would be a new chapter in environmental science and engineering.
Our sincere thanks, first of all, to George Christakos, the Editor-in-Chief of SERRA, for his encouragement and help in making this Special Issue possible in the first place. We thank all the contributors for their interest and willingness to contribute to this Special Issue and also for their hardwork and completion of papers in a timely manner. All the papers submitted to this Special Issue were subjected to a peer-review process, and our sincere appreciation and thanks to the following reviewers (some provided reviews for more than one paper) for their timely and constructive reviews: H. Aksoy, A. C. Bagtzoglou, J. C. Berndtsson, K. J. Beven, J. Chen, A. Cortis, S. W. Franks, E. Gaume, R. S. Govindaraju, K.-L. Hsu, A. W. Jayawardena, K. Jinno, O. Kisi, C. K. Lee, G. Lischeid, D. R. Mailapalli, R. Mantilla, L. Marshall, R. Mehrotra, T. Meixner, A. Montanari, C. Neal, J. P. Norton, J. Olsson, M. Persson, J. D. Phillips, C. E. Puente, G. B. Sahoo, S. Srikanthan, C. B. Uvo, and V. Venugopal.

\section{References}

Beven KJ (2002) Uncertainty and the detection of structural change in models of environmental systems. In: Beck MB (ed) Environmental foresight and models: a manifesto. Elsevier, The Netherlands, pp 227-250

Sivakumar B (2005) Hydrologic modeling and forecasting: role of thresholds. Environ Model Softw 20(5):515-519 